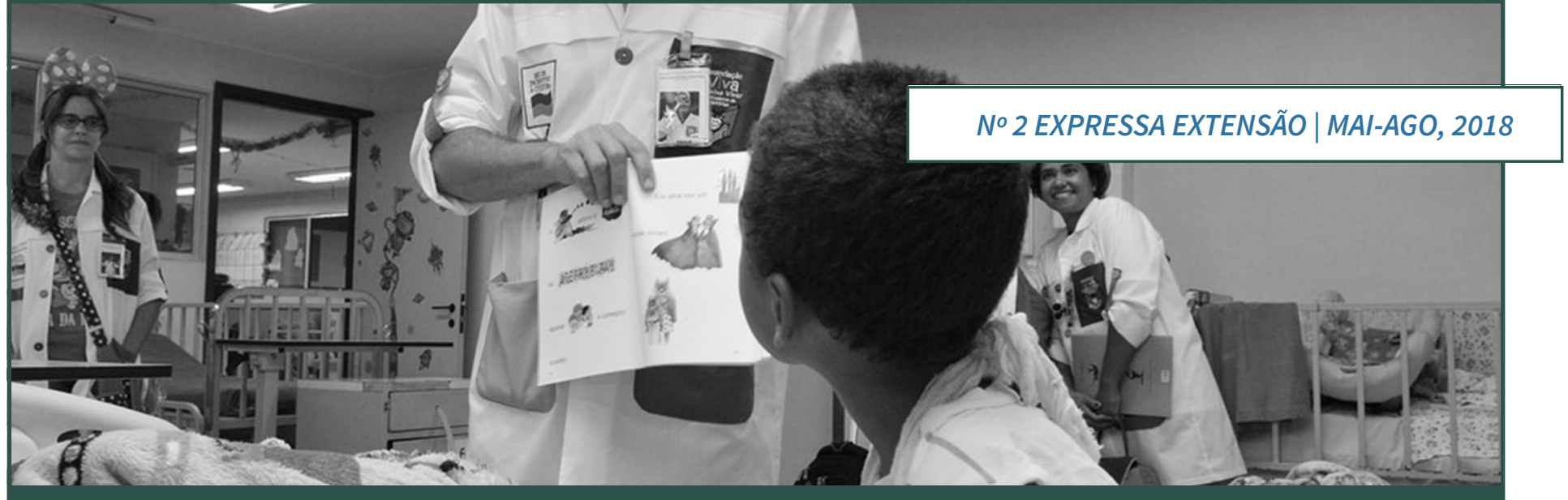

\title{
A EXTENSÃO UNIVERSITÁRIA NA EXPERIÊNCIA DO CUIDADO NA ATENÇÃO A CRIANÇAS HOSPITALIZADAS
}

THE UNIVERSITY EXTENSION IN THE EXPERIENCE OF CARE WITH HOSPITALIZED CHILDREN

Camilla Fernandes Passos Luquete ${ }^{1}$ Vitor Koichi Iwakura Fugimoto ${ }^{2}$

Renan Ferrari Rodrigues ${ }^{3}$ Janaína Dal'laqua Prado ${ }^{4}$ Nathália Sobrinho Baldini ${ }^{5}$

Mariana Fagundes Cinti ${ }^{6}$ Simone Camargo Dias Forte ${ }^{7}$ Marina Chiarato Papeti ${ }^{8}$

Fernando Féssel Toledo ${ }^{9}$ Andrea Perosa Saigh Jurdi ${ }^{10}$

\section{RESUMO}

A Política Nacional de Humanização visa a expressar os princípios do SUS, propiciando nas equipes, trocas solidárias e comprometidas com a dupla tarefa de produção de saúde e produção de cuidado. No PET Saúde da Criança o cuidado em saúde se faz por meio de encontros que visam a conexão das pessoas, não pelas patologias ou diagnósticos, mas pela experimentação da arte, do trabalho e do lazer. Com a dimensão ética de prover cuidado a partir do encontro humano, desenvolvendo a capacidade de cuidar que está associada às capacidades de envolvimento com e de responsabilidade por, foram realizadas intervenções com crianças e acompanhantes. O presente artigo pretende discutir a natureza e a qualidade do cuidado a crianças hospitalizadas e seus acompanhantes a partir das experiências das atividades de extensão e como o cuidado tem ocorrido nes-

\footnotetext{
${ }^{1}$ Camilla Fernandes Passos Luquete- UNIFESP - Brasil - Pedagoga, estudante do Curso de Terapia Ocupacional UNIFESP - campus Baixada Santista, integrante do PET Saúde da Criança, camilla_passos@yahoo.com.br; ${ }^{2}$ Vitor Koichi Iwakura Fugimoto - UNIFESP - Brasil - Estudante do Curso de Psicologia UNIFESP - campus Baixada Santista, integrante do PET Saúde da Criança, vitor_fugimoto@hotmail.com; ${ }^{3}$ Renan Ferrari - UNIFESP - Brasil - Estudante do Curso de Psicologia UNIFESP - campus Baixada Santista, integrante do PET Saúde da Criança, renanferrarirodrigues@hotmail.com; “4 Janaína Dal'laqua Prado - UNIFESP - Brasil - Estudante do Curso de Terapia Ocupacional UNIFESP - campus Baixada Santista, integrante do PET Saúde da Criança, janadallaqua@hotmail. com; ${ }^{5}$ Nathália Sobrinho Baldini - UNIFESP - Brasil - Estudante do Curso de Fisioterapia UNIFESP - campus Baixada Santista, integrante do PET Saúde da Criança, nathy.baldini@hotmail.com; ${ }^{6}$ Mariana Fagundes Cinti - UNIFESP - Brasil - Estudante do Curso de Fisioterapia UNIFESP - campus Baixada Santista, integrante do PET Saúde da Criança, marianafagundesc@hotmail.com; ${ }^{7}$ Simone Camargo Dias Forte - UNIFESP - Brasil - Turismologa, estudante do Curso de Terapia Ocupacional UNIFESP - campus Baixada Santista, integrante do PET Saúde da Criança, simone.diasforte@gmail.com; ${ }^{8}$ Marina Chiarato Papeti - UNIFESP - Brasil - Estudante do Curso de Nutrição UNIFESP - campus Baixada Santista, integrante do PET Saúde da Criança, marinapapeti@gmail.com; ${ }^{9}$ Fernando Féssel Toledo - UNIFESP - Brasil - Estudante do Curso de Educação Física UNIFESP - campus Baixada Santista, integrante do PET Saúde da Criança, toledo.fernando@outlook.com.br; ${ }^{10}$ Andrea Perosa Saigh Jurdi - UNIFESP Brasil - Doutora em Psicologia Escolar e Desenvolvimento Humano pela USP. Docente do Departamento saúde, Educação e Sociedade, docente do curso de Terapia ocupacional da UNIFESP. Desenvolve trabalhos de ensino, pesquisa e extensão na área da infância, andreajurdi@gmail.com.
} 
se ambiente nas ações de saúde. A estratégia metodológica das intervenções foi desenvolvida por oficinas lúdicas na enfermaria pediátrica. 0 ambiente proposto nas oficinas lúdicas propiciou que as atividades se desenvolvessem em espaço compartilhado, e o papel do adulto foi de acolher as diferenças, estar junto quando o brincar não era possível e fornecer segurança suficiente para que o brincar criativo pudesse ser exercido pela criança. $O$ cuidado que afirmamos se faz no campo da produção de saúde, provocando mudanças nas relações com o outro, possibilidades de deslocamentos, de transformações seja no estudante, seja na criança ou no seu acompanhante.

Palavras-chave: Criança hospitalizada. Cuidado. Brincar. Formação interprofissional. Enfermagem.

\section{ABSTRACT}

The Brazilian National Policy of Humanization has the goal of expressing the values of the Unique Health System (SUS Sistem Único de Saúde) enabling solidary exchanges within the teams, with attention to the double mission of promoting health and promoting care. In the PET Children's Health program the care in health is made through meetings that connect people, not because of their pathologies or diagnostics, but because of the experimentation in art, work and leisure. With the ethical dimension of promoting care through human relationships, developing the capacity to care, which is associated to the capacities of involvement with and responsibility for, interventions were made with children and their caretakers. The present paper intends to discuss the nature and quality of the care to hospitalized children and their caretakers, through these experiences of extension activities and how the care happens in this environment in healthcare actions. The methodological strategy of the interventions was developed by ludic workshops at the pediatric ward. The environment proposed in these workshops strengthened the importance of shared space, and the role of the adult was to understand the differences, be present when playing was not possible and to offer enough safety so that the playing could be done by the children. This care is made in the field of healthcare promotion, enabling changes in the relationships with other persons, and personal transformations in all people involved: the student, the children and the caretakers.

Keywords: Hospitalized children. Care. Playing. Interprofessional education. Nursing. 


\section{INTRO DUÇÃO}

A universidade pública tem como uma de suas funções oferecer à comunidade $\mathrm{o}$ acesso ao conhecimento, democratizando o acesso a novas tecnologias e fomentando a criação de novos conhecimentos e intervenções.

Partindo desse ponto de vista, o projeto pedagógico do campus Baixada Santista da Universidade Federal de São Paulo adota como princípio a formação conjunta dos alunos dos diferentes cursos de graduação em momentos de aprendizagens compartilhadas. Nesse modelo de formação duas ou mais profissões aprendem juntas, com e sobre as outras; promovem o trabalho em equipe; desenvolvem parcerias e cooperações entre os profissionais e ampliam a qualidade no cuidado (UNIFESP, 2015).

Na ótica da formação interprofissional a competência se expressa na capacidade de um ser humano cuidar do outro, colocando em ação conhecimentos, habilidades e valores necessários para a prevenção e resolução de problemas de saúde e das demandas sociais em situações específicas do exercício profissional, mobilizando tecnologias para o ato de cuidar (SANTOS, 2011; DELUIZ, 2014).

A formação hoje trata de conhecer os diversos cenários da prática de saúde, colocar-se no lugar do outro (em alteridade) para melhor compreendê-lo; é preciso que os estudantes conheçam o sistema de saúde vigente no país, saibam sobre sua história e se comprometam com ele. Para Ceccim e Pinto (2007), a formação e o exercício profissional não podem seguir linhas paralelas no desenvolvimento de sistemas de saúde, eles precisam manter relações orgânicas. Os autores afirmam que há uma relação imediata entre ambos, pois a formação gera serviços, fixação de profissionais, formação de equipes, desenvolvimento e avaliação de tecnologias de cuidado e assistência.

Optar por esse modelo de educação na formação de profissionais de saúde implica pensar a inserção dos estudantes, desde o início do curso, em cenários da prática profissional, com a realização de atividades educacionais que promovam o desenvolvimento dos desempenhos (capacidades em ação), segundo contexto e critérios. Nesse sentido, deve haver uma estreita parceria entre a academia e os serviços de saúde, instituições sociais e educacionais, criando situações reais de aprendizado.

Tendo como panorama os pressupostos do Projeto Pedagógico do campus, o Programa de Educação Tutorial - PET Saúde da Criança tem como objetivo articular os princípios da indissociabilidade entre ensino, pesquisa e extensão na perspectiva de integrar ações desenvolvidas para a formação profissional do estudante pela produção e difusão de conhecimentos provenientes da experiência 
vivenciada, de modo a possibilitar espaços e oportunidades de conhecimento e aprendizagens que ultrapassam os limites físicos da estrutura acadêmica universitária.

O PET Saúde da Criança baseia suas ações nos princípios da educação interprofissional, valorizando o trabalho em equipe e a integração no processo de ensino e nas atividades de pesquisa e extensão, respeitando a especificidade da formação de cada profissão.

No ambiente hospitalar, o trabalho desenvolvido pelo PET Saúde da Criança compreende o brincar como recurso para acolher crianças e acompanhantes em seu processo de internação, tendo como principal foco a humanização hospitalar, o desenvolvimento infantil e o brincar como potencial recurso no enfrentamento ao processo de hospitalização das crianças. Desenvolve suas atividades na enfermaria pediátrica na qual se encontram crianças atendidas pelo Sistema Único de Saúde (SUS) duas vezes por semana.

Ao oferecer tempo e espaço para as brincadeiras no ambiente hospitalar, as atividades lúdicas desenvolvidas pelo PET Saúde da Criança oferecem às crianças e seus cuidadores acolhimento para externarem suas dificuldades e necessidades, assim como promover um brincar mais criativo, que propicie a elaboração de aspectos relacionados à doença e ao sofrimento físico e emocional provocados pela condição de hospitalização.

Nesse artigo, pretende-se discutir a natureza e a qualidade do cuidado a crianças hospitalizadas e seus acompanhantes a partir das experiências das atividades de extensão e como o cuidado tem ocorrido nesse ambiente nas ações de saúde.

\section{A CONCEPÇÃO DE CUIDADO NO PET SAÚDE DA CRIANÇA}

Segundo o Ministério da Saúde, encontramos na humanização do sistema de saúde como política nacional a possibilidade de um dispositivo valioso para pensar saúde de outra forma que não seja a patologização do indivíduo e seu contexto social. A Política Nacional de Humanização (PNH) visa expressar os princípios do SUS; os modos de operar em diferentes serviços de saúde; propor articulação das práticas que se atualizam nesses estabelecimentos; propiciar, nas equipes, trocas solidárias e comprometidas com a dupla tarefa de produção de saúde e produção de cuidado (BRASIL, 2007).

Para Ayres (2004) os complexos determinantes na relação dos profissionais de saúde e dos pacientes têm no encontro terapêutico a possibilidade do di- 
álogo como a abertura para ouvir o outro com autêntico interesse. O profissional ouve e se faz ouvir, sem se apropriar exclusivamente do discurso tecnocientífico e o acolhimento, que tem como função a capacidade de ouvir e dialogar, têm sido apontados como uma tecnologia importante na humanização em saúde.

Bustamante e McCallum (2014) referem que na saúde o termo cuidado é frequentemente utilizado nas discussões sobre integralidade e humanização das práticas, sendo o cuidado um horizonte normativo que as orienta, envolvendo a construção cotidiana de projetos de vida.

Martines e Machado (2010) definem cuidado, como aquilo que se aglutina sob a forma de ações ou intervenções que colaboram para gerar, organizar ou restabelecer a esperança, a autonomia, a liberdade de escolha, as relações humanas e o sentido da vida. As autoras ressaltam, ainda, que essa relação deva ser o mais simétrica possível e capaz de possibilitar atitudes e espaços de cuidado, abrindo-se para a responsabilização dos laços afetivos e para o encontro intersubjetivo. Nesse sentido, pode-se pensar o cuidado muito mais como uma atitude do que uma ação, revelando assim sua dimensão ética, ancorada no reconhecimento da alteridade (PLASTINO, 2009).

No PET Saúde da Criança compreende-se que o cuidado em saúde se faz por meio dos encontros que visam à conexão das pessoas, não pelas patologias ou diagnósticos, mas pela experimentação da arte, do trabalho e do lazer.

No âmbito hospitalar a noção de cuidado implica pensar em ações mais concretas como intervenções curativas e paliativas. Os profissionais que ali atuam estão diariamente envolvidos na ação de cuidar, debruçando-se nos conjuntos de procedimentos tecnicamente orientados para um bom tratamento. Contudo, no Pet Saúde da Criança ao produzirmos a intervenção com crianças, voltamos a atenção para a atitude de cuidar, para a dimensão ética de prover cuidado a partir do encontro humano, para o desenvolvimento da capacidade de cuidar que está associada às capacidades de envolvimento com e de responsabilidade por.

A ética do cuidado com a vida implica em colocar-se no lugar do outro, compreender suas necessidades e criar um ambiente favorecedor de vida e criação. Nesse sentido, o trabalho desenvolvido na enfermaria tem como recurso a atividade lúdica e como dispositivo, as oficinas lúdicas - lugar e tempo para o brincar compartilhado.

Brincar é um dos direitos assegurados pela legislação e precisa ser resguardado, principalmente quando se constata que ainda há crianças que, por motivos diversos, não usufruem desse direito. Para minimizar ou evitar os traumas da hospitalização, o ambiente hospitalar para as crianças não pode se limi- 
tar ao leito, devendo a unidade pediátrica fornecer condições que atendam às necessidades físicas, emocionais, culturais, sociais, educacionais e de desenvolvimento da criança. Daí, a necessidade de criar um ambiente recreativo, contendo livros, jogos e brinquedos seguros para estimular a auto-expressão da criança. Além disso, é necessário que os profissionais que assistem essas crianças estejam satisfeitos com suas condições de trabalho, fornecendo um atendimento humanizado às crianças e seus acompanhantes, reduzindo o período de hospitalização e os traumas decorrentes do mesmo (LIMA et al., 2006).

Segundo Gomes et al. (2010) o documento tomado como referência na garantia dos direitos da criança hospitalizada é a Resolução n. 41, de 17 de outubro de 1995 elaborado pela Sociedade Brasileira de Pediatria e aprovada pelo Conselho Nacional dos Direitos da Criança e do Adolescente (CONANDA) com vinte itens direcionados a proteger a criança e o adolescente hospitalizados.

Estudos realizados demonstram a importância do brincar para a criança em situação de adoecimento e hospitalização (SOARES; ZAMBERLAN, 2001; MITRE; GOMES, 2004, 2007; MOTTA; ENUMO, 2004; AZEVEDO, 2011; COSTA et al., 2014; VIEIRA; CAZEIRO, 2017).

Parcianello e Fellin (2008) ressaltam o fato que a hospitalização pode ser uma experiência invasiva e traumática para a criança, pois ela vivencia situações que geram insegurança, desconforto e sofrimento psíquico em função do afastamento dos familiares e amigos, pela submissão e passividade; pela restrição ao leito; pela obediência aos procedimentos e pelo perigo real de morte. Além disso, tem o seu corpo exposto a procedimentos de investigação e tratamento, perdendo sua privacidade, ocorrendo assim uma ruptura com sua identidade.

Motta e Enumo (2010) falam sobre as mudanças que ocorrem na vida da criança e ampliam a discussão ao referir que, além dessas mudanças, surgem situações que não faziam parte da sua vida, como a necessidade de se adaptar aos novos horários, receber injeções e outros tipos de medicação, ter que permanecer em um quarto e ser privada de brincar. Essas implicações relatam os prejuízos trazidos por uma hospitalização prolongada e a necessidade e possibilidade de se desenvolverem trabalhos que promovam a humanização da instituição hospitalar.

Na perspectiva do amadurecimento pessoal desenvolvida por D. W. Winnicott (1983), o brincar é sinal de saúde e ganha um estatuto próprio, permitindo vislumbrar a compreensão do indivíduo a partir de sua relação com o ambiente. O brincar winnicottiano é a expressão da criatividade, da possibilidade de o indivíduo criar o mundo por meio de seu gesto espontâneo. Estamos falando de um brincar que tem espaço e lugar para acontecer, tanto na subjetividade de cada um quanto na realidade compartilhada; um brincar que se propõe criativo, pois o 
entrelaçamento com o ambiente faz com que o indivíduo possa criar e transformar, colocar algo de seu no mundo compartilhado (JURDI; AMIRALIAN, 2013).

Ao oferecer tempo e espaço para as brincadeiras no ambiente hospitalar, as atividades lúdicas desenvolvidas pelo PET Saúde da Criança oferecem às crianças e seus cuidadores acolhimento para externarem suas dificuldades e necessidades, assim como promover um brincar mais criativo, que propicie a elaboração de aspectos relacionados à doença e ao sofrimento físico e emocional, provocados pela condição de hospitalização para uma situação mais agradável e confortável. A atuação no espaço hospitalar auxilia na mudança de comportamentos dessa população e proporciona benefícios para além da atenção à doença.

\section{OFICINAS LÚDICAS - ESPAÇO DE ENCONTRO E CUIDADO INFANTIL}

O grupo do PET Saúde da Criança é composto por dezoito estudantes dos seis cursos de graduação da saúde que compõem o Instituto Saúde e Sociedade do campus Baixada Santista da Universidade Federal de São Paulo. São estudantes de fisioterapia, psicologia, serviço social, educação física, nutrição e terapia ocupacional que se dividem em dois grupos que oferecem oficinas lúdicas em uma enfermaria pediátrica do SUS em um hospital geral de um município do Estado de São Paulo.

Um grupo atua na segunda-feira a tarde e outro na quinta-feira pela manhã e são responsáveis por elaborarem um cronograma de atividades e confeccionarem o material necessário para as oficinas lúdicas. Toda essa atividade tem a supervisão semanal da tutora na qual são discutidas as intervenções, dúvidas ou dificuldades que surgem nas atividades em campo, além de seminários teóricos e oficinas de atividades.

O registro das atividades é realizado por meio de relatórios que descrevem o que foi realizado e como os estudantes se colocaram frente às situações que emergiram. O cenário de prática é a enfermaria geral pediátrica do hospital, cuja estrutura totaliza 51 leitos, 16 quartos, uma sala de procedimentos, WC masculino e WC feminino, sala de medicação, copa de funcionários, rouparia, posto de enfermagem e depósito de materiais de limpeza. Em relação aos profissionais, totalizam 53, sendo esses técnicos e auxiliares de enfermagem e enfermeiros, além de uma camareira, duas profissionais da limpeza, duas pedagogas, nove enfermeiros, trinta auxiliares, seis técnicos de enfermagem e um médico chefe da pediatria. O hospital também conta com uma equipe multidisciplinar que comparece conforme solicitado, sendo esses assistentes sociais, fonoaudiólogos, nutricionistas, psicólogos, pedagogos, terapeutas ocupacionais e fisioterapeutas. Os 
profissionais de fisioterapia são plantonistas e é solicitado um a cada passagem de plantão, resultando dois por dia, e estes não são fixos.

A ala da pediatria possui uma brinquedoteca, a qual é coordenada pelo grupo Rotary Club, com apenas um profissional responsável e com horário de funcionamento de duas horas nos períodos da manhã e tarde. Além da brinquedoteca, há um espaço externo com alguns brinquedos para que as crianças possam brincar em outros momentos.

Para realizar as oficinas lúdicas, os estudantes levam até a enfermaria diversos recursos lúdicos, tais como: brinquedos diversos para diferentes faixas etárias, tinta, lápis, contação de história e músicas. Primeiro se dirigem aos leitos convidando as crianças e seus acompanhantes para as brincadeiras e as crianças que podem sair do leito acompanham os estudantes até a parte externa da enfermaria, onde há um pequeno playground e participam das oficinas. Para as crianças acamadas e impossibilitadas de saírem do leito, alguns estudantes se dirigem ao leito e oferecem atividades lúdicas para as mesmas. É importante ressaltar que as crianças têm liberdade para recusar ou aceitar as brincadeiras oferecidas. Para Jurdi; Sá; Panciera (2017) as oficinas lúdicas utilizam diversos recursos que privilegiam o tempo para brincar, com a construção de um espaço coletivo e promotor de trocas e interações, propiciando a autonomia da criança no processo de adoecimento.

Walter Benjamin (1984) refere que trabalhar com crianças nos coloca um desafio; ver o mundo através de seu olhos e vivenciá-lo a partir de suas atividades, de seus corpos, compreendê-lo com base em suas ideias. Compreende-se, assim, que a criança pode falar de suas necessidades, de suas demandas e ela é o foco principal do cuidado que aqui se fala.

Jurdi, Sá e Panciera (2017) referem que as oficinas tem sido utilizadas como dispositivos coletivos de proteção e, em relação à atenção e cuidado a crianças, esse modelo de intervenção permite a fala de diversos atores: a criança, os acompanhantes e os profissionais que a atendem, além de ser necessário pensar em um dispositivo flexível que pudesse utilizar diversos recursos e linguagens que nos aproximassem do campo da infância.

As atividades desenvolvidas pelo Pet Saúde da Criança foram iniciadas em 2011 e, desde então, mantém as atividades na enfermaria pediátrica e, em 2018 inicia mais um cenário de práticas em um Centro de Atenção Psicossocial Infanto Juvenil (CAPSij) do município. As atividades relatadas nesse artigo são referentes ao período de fevereiro a dezembro de 2017 e os trechos de relato foram extraídos dos relatórios dos estudantes, os quais nomeamos de E1, E2, ... , E5. 


\section{RELATOS DA EXPERIÊNCIA}

As atividades extensionistas do PET Saúde da Criança partem do pressuposto de que é preciso compreender as vicissitudes a que estão expostas as crianças e acompanhantes no ambiente hospitalar, e é a partir da compreensão das dificuldades que se torna possível produzir intervenções que favoreçam o desenvolvimento saudável. Pode-se dizer que essas intervenções são preventivas, pois tem como foco principal as modificações das condições ambientais (AMIRALIAN, 2013).

Para a autora, as intervenções preventivas são utilizadas nos casos em que se acredita que modificações focadas nas condições ambientais são valiosas para prevenir ou modificar situações que podem vir a causar dificuldades ao desenvolvimento.

A partir dos relatos dos extensionistas, foi possível elencar três condições básicas que expressam como o cuidado é considerado e exercido nas intervenções: a primeira condição é criar um ambiente favorecedor para que o brincar aconteça. Winnicott (1983) refere que para brincar a criança precisa se sentir segura e ter confiança no ambiente que a cerca, e aos estudantes extensionistas cabe a função de proporcionar um ambiente suficientemente bom, adaptando-se às necessidades que as crianças apresentam. Como exemplo, pode-se lembrar de crianças com dores, ou que estão há muito tempo internadas e precisam de uma atenção especifica, ou então, crianças mais agitadas que exigem uma atenção maior. Para cada uma delas é preciso um olhar especifico e um cuidado singular. Como exemplo um trecho extraído do relato da estudante E1 e E2:

"Tia, tem que andar?". Sem saber o que ele tinha respondi: "Você quer andar ou não?". Ele: "Eu não posso". Na hora falei: "Então é uma brincadeira que não precisa andar, pode ir lá fora que vamos brincar todos juntos". Ele abriu um sorriso e logo em seguida estava sentado na área externa no colo da mãe junto com os outros e brincou. (E1)

Fomos à ala de queimados e quando chegamos à brinquedoteca havia duas crianças internadas. Com as crianças, brincamos de casinha com os brinquedos que levamos e com os que já estavam lá, também levamos lápis e papel, mas eles não usaram tanto. Na brincadeira de casinha, tanto o menino quanto a menina se expressaram muito, fazendo comida e dando mamadeira para os bebês, a acompanhante do menino, lembrou-se dele ter se queimado quando mexia no fogão. No começo pensei que talvez não fosse muito bom brincar disso por lembrar-se do acontecimento, que acontece muito com as crianças, mas depois percebi que era possível trabalhar com o enfrentamento da situação.

Depois que a brinquedoteca fechou, a pedagoga perguntou se queríamos deixar uma mesa do lado de fora para continuar a brincadeira, aceitamos e continuamos com as crianças e os acompanhantes. Na hora de ir embora, E. (menina que participou da oficina) começou a ficar brava, pois íamos pegar todos os nossos brinquedos. Ela começou a jogar tudo no chão e não querer mais falar com a gente, tentamos acalma-la e fazê-la entender que estava na hora e que outro dia teria mais, mas ela ficou emburrada. Então incentivamos o A. (menino que participou da oficina) a guardar os brinquedos com a gente. Quando íamos sair pela porta, E.(menina que participou da oficina) nos chamou e nos deu tchau, pedindo uma folha e um lápis para ela, já que o A.( menino que participou da oficina) também tinha recebido. Entregamos e fomos embora da ala, nos sentindo melhor pelos dois terem aceito o encerramento da brincadeira, apesar da dificuldade com a E. (E2) 
Por muitas vezes os estudantes relatam o receio que as atividades lúdicas possam trazer à tona situações que possam causar sofrimento para as crianças, pois remetem às experiências traumáticas. Nesse processo de aprendizado foi possível discutir que o brincar e as oficinas propiciam que as crianças elaborem e revivam situações por meio de fantasias, das atividades lúdicas. O brincar surge como possibilidade que a criança tem de viver criativamente, de vivenciar processos de saúde, de reverter processos de amadurecimentos interrompidos. Na prática cotidiana, o brincar propicia às crianças estarem em contato com o mundo, com a cultura e se apropriar desses elementos, revelando uma maneira de ser, de estar no mundo e de se expressar.

Outro aspecto que surge no relato acima é a dificuldade da criança em finalizar a brincadeira e nos remete a outro aspecto fundamental no cuidado a crianças hospitalizadas: o vínculo. Os estudantes são orientados a cuidar para que o vínculo aconteça e possa permanecer ao longo das intervenções, assim a menina que não queria interromper a brincadeira demonstrou a falta que iria fazer a relação do brincar desenvolvida com os estudantes. A alternativa a essa falta é presentificar a ausência e permitir que uma parte dessa lembrança e afeto permaneça mesmo sem a presença dos estudantes e foi necessário deixar algo, um objeto ou uma atividade para que ela pudesse suportar a espera de uma semana.

O terceiro aspecto se refere às narrativas dos acompanhantes e à escuta qualificada das angústias, das histórias de vida, da possibilidade de ser ouvido, como por exemplo, a cena relatada a seguir pela estudante E5:

Enquanto o grupo fazia a atividade/brincadeira com um garoto em um dos quartos grandes, eu estava neste mesmo quarto conversando com uma mãe que estava com o filho - um garotinho - no colo. Iniciei a conversa perguntando se ele estava dormindo, ela respondeu que não, que era dor mesmo. Continuei a conversa perguntando por que estavam ali e há quanto tempo, foi aí que ela começou o desabafo, bastante irritada, nervosa e ao mesmo tempo preocupada com a situação do filho. (E5)

Segundo Joaquim et al. (2017), o processo de adoecimento e hospitalização infantil causa transformações na rotina de todo o núcleo familiar, sendo que a internação da criança pode causar sofrimento aos membros da família, afetando o equilíbrio e os papéis ocupados por eles.

Além disso, os autores chamam a atenção para as condições que as famílias encontram no ambiente hospitalar: falta de acomodações adequadas para descanso e sono, ruídos do ambiente e choro da criança associados ao sofrimento pelo período de hospitalização. Além disso, a alternância entre domicílio e o hospital gera desgaste físico e emocional; os sentimentos de culpa, medo e ansiedade diminuem a qualidade de vida da família e comprometem as ações de suporte oferecidas por estes ao paciente (JOAQUIM et al., 2017) 
Para Menezes (2010), quando o processo de doença da criança culmina em hospitalização, a família deve ser acolhida de forma cuidadosa, principalmente na recepção quando a família chega à instituição hospitalar, pois representa um momento decisivo para os acompanhantes. Para a autora, mais do que participar dos cuidados da criança, os acompanhantes têm a necessidade de se sentirem acolhidos e seguros no ambiente hospitalar. Na pesquisa realizada pela autora com os acompanhantes de crianças hospitalizadas, os resultados apresentaram aspectos negativos e positivos apontados pelos acompanhantes entrevistados. Como aspectos negativos na relação com a equipe de profissionais do hospital ressalta-se a banalização do sofrimento, o contato restrito com o médico, a falta de atenção na conversa, não ter uma relação de proximidade. Porém, os acompanhantes relatam que quando há, entre as atitudes do profissional, respeito, o uso de linguagem acessível que considerem as diferenças culturais, a franqueza, e a gentileza manifestada através de brincadeiras e sorrisos, o aprendizado sobre as informações e procedimentos, sobre cuidados com o filho hospitalizado, o cuidado com outros filhos e o cuidado com si mesmo, há ganhos no processo de hospitalização.

Para o PET Saúde da Criança, o acolhimento às queixas, às dificuldades encontradas pelos acompanhantes e a oferta de um espaço lúdico, no qual a ludicidade possa se manifestar mesmo em um momento de dor e sofrimento, são atitudes de cuidado com a vida.

A tia avó de J. (1 ano e 3 meses), elogiava o trabalho desenvolvido pelo PET, por estarmos lá brincando e levando alegria para as crianças. Enquanto eu brincava com sua neta, sua tia avó estava desabafando sobre o caso de J., que está internada há 14 dias com broncopneumonia e sua mãe está com tuberculose e também está sob cuidados há 15 dias (portanto não pode ficar com a filha no hospital), e o pai de J. trabalha e cuida do outro filho de 5 anos. Então quem fica com J. no hospital é ela e sua irmã, avó da menina. Por estar longe de sua família (mãe, pai e irmão), ela não para de chorar todos esses dias, e sua tia estava falando que nada a alegrava, e ficou muito feliz em ver como a atividade do PET entreteu a criança, e relatou que filmou uma parte para mandar para mãe dela. (E4)

Ao oferecer espaços de ludicidade aos acompanhantes, resgatam-se as experiências lúdicas, as memórias da infância e promove-se uma proximidade de vida e cuidado com a criança que está próxima. As atividades lúdicas têm também uma função educativa, como quando levamos brincadeiras associadas a temas como alimentação, amamentação, o cuidado a saúde, higiene, prevenção, dentre outros. 
O relato a seguir mostra com essas atividades são propostas:

\begin{abstract}
A atividade de hoje foi amamentação e alimentação saudável. Utilizamos um jogo da memória com as crianças e um jogo de verdadeiro ou falso com as mães e acompanhantes foi possível introduzir e conversar sobre a importância da amamentação, tirando dúvidas, esclarecendo pontos e dando a oportunidade das mães conversarem sobre o que ia sendo falado. Com as crianças, fizemos o jogo da memória utilizando fotos de alimentos como arroz, feijão, legumes, frutas, doces e outros. Após a brincadeira, pedimos para que eles montassem com as fotos, os pratos que eles comiam em casa e os alimentos que mais gostavam e porque, tentamos incentivar o consumo principalmente de frutas e legumes. Tivemos uma interação muito boa das crianças maiores, que brincaram conosco um longo tempo na parte de fora. Com as mães, conseguimos fazer uma rodada do jogo e ficaram surpresas e interessadas com as afirmações verdadeiras e falsas e compartilharam conosco momentos que se lembraram do tempo que ainda amamentavam. Foi possível conversar com uma mãe que estava com a filha recém-nascida fazendo banho de luz devido à icterícia. Quando passei por esse quarto, essa mãe disse que o leite dela era fraco, as perguntas e respostas foram imprescindíveis para informar aquela mãe e ela ter certeza das respostas, pois conversamos bastante e ela tinha conhecimento de muitas informações. (E5)
\end{abstract}

A escuta qualificada, o respeito com as histórias de vida, com o contexto atual permite que os estudantes do PET conheçam e possam ajudar no que for possível, pois se observa que, muitas vezes, apenas escutar um desabafo e as preocupações já traz conforto para quem está sofrendo. Por outro lado, o estudante, ao conhecer histórias de vida diversas e experiências diversas exercita o que é mais importante nas relações de cuidado como profissional de saúde: a alteridade, a possibilidade de colocar-se no lugar do outro.

\title{
CONSIDERAÇÕES FINAIS
}

Nesse artigo pretendeu-se discutir a natureza e a qualidade do cuidado a crianças hospitalizadas e seus acompanhantes a partir das experiências das atividades de extensão e como o cuidado tem ocorrido nesse ambiente nas ações de saúde.

A ética do cuidado com a vida implica em colocar-se no lugar do outro, compreender suas necessidades e criar um ambiente favorecedor de vida e criação. Nesse sentido, o trabalho desenvolvido na enfermaria tem como recurso, a atividade lúdica, e como dispositivo, as oficinas lúdicas - lugar e tempo para o brincar compartilhado.

Para promover ações que tenham como foco o cuidado com a vida de tantas crianças que passam pela enfermaria, os estudantes do PET utilizam o brincar e proporcionam um ambiente suficientemente bom para que a criança se sinta segura para brincar. O ambiente proposto nas oficinas lúdicas potencializou a importância do espaço compartilhado e o papel do adulto foi de acolher 
as diferenças, estar junto quando o brincar não era possível e fornecer segurança suficiente para que o brincar criativo pudesse ser exercido pela criança.

O cuidado que afirmamos se faz no campo da produção de saúde, provocando mudanças nas relações com o outro, possibilidades de deslocamentos, de transformações seja no estudante, seja na criança ou no seu acompanhante.

\section{REFERÊNCIAS}

AMIRALIAN, M. L. T. M. Prevenção e Tratamento. In: (org).

Saúde e desenvolvimento: intervenções a partir da teoria do amadurecimento de D. W. Winnicott. São Paulo: Vetor, 2013.

AYRES, J. R. C. M. Cuidado e reconstrução das práticas de saúde. Interface: Comunicação, Saúde, Educação, Botucatu, v. 8, n. 14, p. 73-92, set./fev. 2004.

AZEVEDO, A. V. dos S. O brincar da criança com câncer no hospital: análise da produção científica. Estudos de Psicologia, Campinas, v. 28, n. 4, p. 565-572, 2011.

BENJAMIN, W. Reflexões: a criança, o brinquedo, a educação. São Paulo: Summus, 1984.

BRASIL, Ministério da Saúde. Secretaria de Atenção à Saúde. Política Nacional de Humanização da Saúde: documento base. 4. ed. Brasília: Ministério da Saúde, 2007.

BUSTAMANTE, V.; MCCALLUM, C. Cuidado e construção social da pessoa: contribuições para uma teoria geral. Physis Revista de Saúde Coletiva, Rio de Janeiro, v. 24, n. 3, p. 673-692, 2014.

CECCIM, R. B.; PINTO, L. F. A formação e especialização de profissionais de saúde e a necessidade política de enfrentar as desigualdades sociais e regionais. Rev. Bras. Educ. Med., Rio de Janeiro, v. 31, n. 3, p. 266-277, dez. 2007.

COSTA, S. A. F. et al. Brinquedoteca Hospitalar: reconstruindo a história de sua criação e implantação. Hist. Enf. Rev. Eletr. (HERE), v. 5, n. 2, p. 206-223, ago./dez. 2014. Disponível em: <http://www.abennacional.org.br/centrodememoria/here/ vol5num2artigo14.pdf>. Acesso em: 02 fev.2018.

DELUIZ, N. O modelo das competências profissionais no mundo do trabalho e na educação: implicações para o currículo. Disponível em: <http://www.senac. br/informativo/BTS/273/boltec273b.htm>. Acesso em: 03 mar. 2017. 
GOMES, I. L.; CAETANO, R.; JORGE, M. S. Knowledge of health professionals about the rights of hospitalized children: an exploratory study. Ciên. Saúde Colet., v. 15, p. 463-70. 2010.

JOAQUIM, R. H. V. T.; BARBANO, L. M.; BOMBARDA, T. B. Necessidades das famílias em enfermaria pediátrica: a percepção dos próprios autores. Ver. Ter. Ocup. Univ. São Paulo, v. 28, n. 2, p. 181-189, 2017.

JURDI, A. P. S.; AMIRALIAN, M. L. T. M. Ética do cuidado: a brinquedoteca como espaço de atenção a crianças em situação de vulnerabilidade. Interface: Comunicação, Saúde, Educação, Botucatu, v. 17, n. 45, p. 275-85, 2013.

JURDI, A. P. S.; SÁ, C. dos S. C.; PANCIERA, S. D. P. Oficinas lúdicas: lugar e tempo para brincar. In: JURDI, A. P. S.; SILVA, C. C. B.; BRUNELLO, M. I. B (orgs). Cirandas do brincar: formações e práticas profissionais. São Paulo: Ed. Unifesp, 2017.

LIMA, F. E. T.; JORGE, M. S. B.; MOREIRA, T. M. M. Humanização hospitalar: satisfação dos profissionais de um hospital pediátrico. Revista Brasileira de Enfermagem, Brasília, v. 59, n. 3, p. 291-296, 2006.

MARTINES, W. R. V.; MACHADO, A. L. Produção de cuidado e subjetividade. Revista Brasileira de Enfermagem, Brasília, v. 63, n. 2, p. 328-33, 2010.

MENEZES, M. A criança e sua rede familiar: significaçãoes do processo de hospitalização. Tese (Doutorado em Psicologia) - Programa de Pós Graduação em Psicologia. Universidade Federal de Santa Catarina. Centro de Filosofia e Ciências Humanas, 2010.

MITRE, R. M. A; GOMES, R. A promoção do brincar no contexto da hospitalização infantil como ação de saúde. Ciência \& Saúde Coletiva, v. 9, n. 1, p. 147-154, 2004.

A perspectiva de profissionais de saúde sobre a promoção do brincar em hospitais. Ciência \& Saúde Coletiva, v. 12, n. 5, p. 1277-1284, 2007.

MOTTA, A. B.; ENUMO, S. R. F. Brincar no hospital: estratégias de enfrentamento da hospitalização infantil. Psicologia em Estudo, Maringá, v. 9, n. 1, p. 19-28, 2004.

Intervenção psicológica lúdica para o enfrentamento da hospitalização em crianças com câncer. Psic. Teor. e Pesq., Brasília, v. 26, n. 3, p. 445-454, set. 2010. 
PARCIANELLO, A. T.; FELIN, R. B. E agora doutor, onde vou brincar? Barbarói, Santa Cruz do Sul, n. 28, jan./jun. 2008.

PLASTINO, C. A. A dimensão constitutiva do cuidar. In: MAIA, M. S. (org.) Por uma ética do cuidado. Rio de Janeiro: Garamond, 2009.

SANTOS, W. S. dos. Organização curricular baseada em competência na educação médica. Rev. Bras. Educ. Med., [Rio de Janeiro], v. 35, n. 1, p. 86-92, 2011.

SOARES, M. R. Z.; ZAMBERLAN, M. A. T. A inclusão do brincar na hospitalização infantil. Revista Estudos de Psicologia, Campinas, v. 18, n. 2, p. 64-69, 2001.

UNIFESP. Universidade Federal de São Paulo. Projeto político-pedagógico do curso de Terapia Ocupacional da Universidade Federal de São Paulo. São Paulo, 2015. Disponível em: <http://www.unifesp.br/campus/san7/projetos-politico-pedagogicos>. Acesso em: 05 fev. 2018

VIEIRA, S. R.; CAZEIRO, A. P. M. Análise dos jogos e brincadeiras para o contexto hospitalar. Rev Interinst. Bras. Ter. Ocup. Rio de Janeiro, v. 1, n. 2, p. 127-148, 2017.

WINNICOTT, D. W. O ambiente e os processos de maturação: estudos sobre a teoria do desenvolvimento emocional. Porto Alegre: Artes Médicas, 1983.

Data de recebimento: 03 de março de 2018.

Data de aceite para publicação: 21 de maio de 2018. 